\title{
A small-molecule inhibitor of UBE2N induces neuroblastoma cell death via activation of p53 and JNK pathways
}

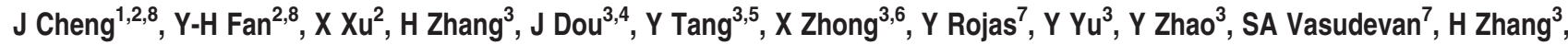 \\ JG Nuchtern ${ }^{7}$, ES Kim ${ }^{7}, X$ Chen $^{1}, \mathrm{~F} \mathrm{Lu}^{*, 1}$ and J Yang ${ }^{\star 2}$
}

Neuroblastoma (NB) is the most common extracranial neoplasm in children. In NB, loss of p53 function is largely due to cytoplasmic sequestration rather than mutation. Ubiquitin-conjugating enzyme E2 N (UBE2N), also known as Ubc13, is an E2 ubiquitin-conjugating enzyme that promotes formation of monomeric p53 that results in its cytoplasmic translocation and subsequent loss of function. Therefore, inhibition of UBE2N may reactivate p53 by promoting its nuclear accumulation. Here, we show that NSC697923, a novel UBE2N inhibitor, exhibits potent cytotoxicity in a panel of NB cell lines evidenced by its ability to induce apoptosis. In p53 wild-type NB cells, NSC697923 induced nuclear accumulation of p53, which led to its increased transcriptional activity and tumor suppressor function. Interestingly, in p53 mutant NB cells, NSC697923 induced cell death by activating JNK pathway. This effect was reversible by blocking JNK activity with its selective inhibitor, SP600125. More importantly, NSC697923 impeded cell growth of chemoresistant LA-N-6 NB cell line in a manner greater than conventional chemotherapy drugs doxorubicin and etoposide. NSC697923 also revealed in vivo antitumor efficacy in NB orthotopic xenografts. Taken together, our results suggest that UBE2N is a potential therapeutic target in NB and provide a basis for the rational use of UBE2N inhibitors like NSC697923 as a novel treatment option for NB patients.

Cell Death and Disease (2014) 5, e1079; doi:10.1038/cddis.2014.54; published online 20 February 2014

Subject Category: Cancer

Neuroblastoma (NB) is derived from neural crest cells and is the most common extracranial tumor in children, accounting for $15 \%$ of all pediatric cancer-related deaths. ${ }^{1,2}$ Approximately $40 \%$ of the patients diagnosed with NB will fall under the high-risk category based on factors such as age at diagnosis, stage, tumor histology, MYCN status, and DNA ploidy. ${ }^{3,4}$ Despite intensive multi-modal therapy, the prognosis for high-risk NB patients remains poor with a high rate of relapse and a 5 -year survival rate of $30 \% .^{4,5}$ Thus, innovative strategies are urgently needed to further improve the efficacy of NB treatment. Unlike many other tumor types, p53 mutations rarely occur in NB suggesting that restoration of p53 function may be a potential adjunct to current treatment regimens of $\mathrm{NB} .^{6}$

The 553 protein has been studied extensively due to its key role in tumor suppression. It functions as a transcription factor and induces cell cycle arrest, apoptosis and cellular senescence by controlling a variety of signaling pathways in response to stress signals. ${ }^{7}$ Upon its activation, p53 will dissociate with mouse double minute 2 homolog (MDM2), an E3 ubiquitin ligase, and translocate to the nucleus, where it activates the target genes. ${ }^{8-10}$ As the majority of p53 tumor suppressor functions are achieved by its transcriptional activity, nuclear localization of the protein is essential. Although mutation is the most common mechanism of p53 inactivation in adult tumors, significant fractions of wild-type p53 protein are found in the cytoplasm of NB, suggesting that sequestration of $\mathrm{p} 53$ in the cytoplasm in NB represents another important mechanism for abrogating p53 function. ${ }^{11-13}$ Thus, pharmacological restoration of nuclear p53 by small molecules may have a major clinical impact on targeted drug design in NB.

\footnotetext{
${ }^{1}$ Department of Microbiology \& Infectious Disease Center, School of Basic Medical Science, Peking University Health Science Center, Beijing 100191, China; ${ }^{2}$ Department of Pediatrics, Texas Children's Cancer Center, Dan L. Duncan Cancer Center, Baylor College of Medicine, Houston, TX 77030, USA; ${ }^{3}$ Department of Pathology, University of Texas MD Anderson Cancer Center, Houston, TX 77030, USA; ${ }^{4}$ Xinjiang Key Laboratory of Plant Resources and Natural Products Chemistry, Xinjiang Technical Institute of Physics and Chemistry, Chinese Academy of Sciences, Urumqi, Xinjiang 830011, China; ${ }^{5}$ Department of Hematology, Tongji Hospital, Tongji Medical College, Huazhong University of Science and Technology, Wuhan, Hubei 430030, China; ${ }^{6}$ Department of General Surgery, the Second Affiliated Hospital of Harbin Medical University, Harbin, Heilongjiang 150086, China and ${ }^{7}$ Division of Pediatric Surgery, Michael E. DeBakey Department of Surgery, Dan L. Duncan Cancer Center, Baylor College of Medicine, Houston, TX 77030, USA

${ }^{*}$ Corresponding author: F Lu, Department of Microbiology \& Infectious Disease Center, School of Basic Medical Science, Peking University Health Science Center, 38 Xueyuan Road, Beijing 100191, China. Tel: +86 108280 5136; Fax: +86 108280 5136; E-mail: lu.fengmin@ @sc.pku.edu.cn or J Yang, Department of Pediatrics, Texas Children's Cancer Center, Dan L. Duncan Cancer Center, Baylor College of Medicine, One Baylor Plaza, Houston, TX 77030, USA. Tel: 1832824 4572; Fax: 1832825 1206; E-mail: jianhuay@bcm.edu

${ }^{8}$ These authors contributed equally to this work.

Keywords: neuroblastoma; UBE2N inhibitor; NSC697923; p53; JNK

Abbreviations: NB, neuroblastoma; UBE2N, ubiquitin-conjugating enzyme E2 N; Dox, doxorubicin; VP16, etoposide; MDM2, mouse double minute 2 homolog; NF- $\kappa$ B, nuclear factor kappa B; IKK, I $\kappa$ B kinase; MAPK, mitogen-activated protein kinase

Received 25.9.13; revised 09.12.13; accepted 17.12.13; Edited by G Raschellá
} 
Subcellular localization of the p53 protein is a dynamic process and is tightly regulated by different molecular mechanisms. Recent studies have revealed the potential role of ubiquitin-conjugating enzyme E2 N (UBE2N) as a novel regulator of $\mathrm{p} 53$ by reducing its transcriptional activity. ${ }^{14}$ UBE2N, also known as Ubc13, is a member of the E2 ubiquitin-conjugating enzyme family that mediates the synthesis of Lysine 63-linked polyubiquitination chains. UBE2N mainly functions together with its cofactors Uev1A and Mms2, both of which are ubiquitin-conjugating enzyme variants (Uevs) that lack the active-site cysteine residues. ${ }^{15-17}$ For its activity, UBE2N forms an obligate heterodimer with Uev1A to positively regulate nuclear factor kappa $\mathrm{B}(\mathrm{NF}-\kappa \mathrm{B})$ signaltransduction pathway, while in complex with Mms2, UBE2N is required for DNA damage repair. ${ }^{18}$ UBE2N has also been suggested to have a critical role in activation of mitogenactivated protein kinases (MAPKs) signaling. ${ }^{19}$ With regard to p53, UBE2N associates with p53 and increases the cytoplasm pool of monomeric p53, thereby inhibiting nuclear tetramerization of $\mathrm{p53} .^{14,20}$ Owing to the critical role of UBE2N in cytosolic sequestration of wild-type p53 and the fact that cytosolic sequestration of wild-type p53 is present in most NB cases, we hypothesized that pharmacological inhibition of UBE2N would promote p53 nuclear translocation and its subsequent activation in NB.

Several small-molecule compounds targeting UBE2N or the formation of UBE2N-Uev1A complex have been recently developed. ${ }^{21-24}$ NSC697923 is one such compound that specifically targets UBE2N-Uev1A. A previous study has shown that NSC697923 inhibits the proliferation and survival of diffuse large B-cell lymphoma (DLBCL) cells in vitro. ${ }^{25}$ However, the potential antitumor efficacy of NSC697923 has not yet been assessed in vivo. Here we investigated the utility of NSC697923 in an orthotopic NB mouse model. We have demonstrated that NSC697923 induces NB cell death via promoting nuclear importation of p53 in p53 wild-type NB cells. In addition, we have shown that it also induces cell death in p53 mutant NB cells by activation of JNK-mediated apoptotic pathway. Furthermore, NSC697923 also exhibits a greater cytotoxic effect on a chemoresistant NB cell line, LA-N-6, than conventional chemotherapy drugs doxorubicin (Dox) and etoposide (VP16). Taken together, our findings shed light on the viability of UBE2N as a potential molecular target in the treatment of NB and suggest that NSC697923 may serve as a novel antitumor drug for NB patients.

\section{Results}

UBE2N inhibitor NSC697923 shows cytotoxic effect on NB cell lines. To explore the effects of UBE2N inhibition on NB cell lines, we first tested the baseline level of UBE2N in a panel of six NB cell lines including three MYCN-amplified cell lines: IMR32, NGP, NB19 and three MYCN-nonamplified cell lines: CHLA-255, SK-N-AS, and SH-SY5Y (Supplementary Table 1). All cell lines showed obvious expression of UBE2N, suggesting that this may be an ideal target in NB (Figure 1a). We then examined its cytotoxicity on the above six NB cell lines. Treatment with NSC697923 significantly reduced NB cells viability in a dose-dependent manner (Figure 1b). NSC697923 also induced cell death in the p53 non-functional cell line SK-N-AS and p53 partially functional cell line NB-19 (Figure 1b, Supplementary Table 1). Morphological images of six NB cell lines after treatment also confirmed the cytotoxic effect of NSC697923 (Figure 1c and Supplementary Figure 1a). Consistent with the above results, flow cytometry analysis showed that NSC697923 induced apoptosis in all NB cell lines tested (Figure 1d and Supplementary Figure 1b). These data demonstrate that UBE2N inhibitor, NSC697923, can induce apoptosis in NB cell lines.

NSC697923 suppresses colony-formation potential of NB cells. To evaluate whether NSC697923 also inhibits colony-formation ability of NB cell lines, clonogenic assay and soft agar assay were performed using a panel of six NB cell lines. All cell lines tested showed a significant decrease in the ability to form colonies after NSC697923 treatment when compared with the untreated control (Figure 2a). Furthermore, NSC697923 also significantly attenuated anchorage-independent NB cell growth in a dose-dependent manner (Figure 2b). These data indicate that NSC697923 inhibits both anchorage-dependent and -independent colony formation of NB cells.

NSC697923 induces apoptosis by promoting p53 nuclear localization in p53 wild-type NB cell lines. Previous studies have revealed the role of UBE2N in regulating $\mathrm{p} 53$ localization and transcriptional activity. ${ }^{14,20}$ Therefore, we tested whether NSC697923 could induce p53 nuclear localization in NB cell lines. First, we extracted cytoplasmic and nuclear proteins from p53 wild-type SH-SY5Y and IMR32 cells, as well as p53 mutant SK-NAS cells before and after NSC697923 treatment. Our results showed that wild-type p53 level in nucleus was significantly elevated after NSC697923 treatment, but cytoplasmic p53 remained unchanged (Figure $3 \mathrm{a}$ ). To directly visualize p53 localization, we used confocal microscopy to monitor p53 localization in SH-SY5Y, IMR32, and SK-N-AS cell lines. Treatment with NSC697923 substantially increased the percentage of cells exhibiting absolute nuclear p53 localization in two p53 wild-type cell lines, but not in p53 mutant SK-N-AS cell line (Figures $3 b$ and $c$ ). These results suggest that inhibition of UBE2N increases nuclear accumulation of p53 in NB cells.

To further demonstrate that NSC697923 activates p53 by inducing its nuclear translocation instead of increasing its total amount, we compared p53 activation induced by NSC697923 and Dox. As shown in Figure 3d, although NSC697923 did not significantly increase total p53 level as Dox did in SH-SY5Y cells, it more potently promoted p53-targeted gene p21 expression compared with Dox. This result further supported that NSC697923 exhibits its effect primarily through inducing p53 nuclear translocation but not increasing its total amount.

We next assessed p53 transcriptional activity by using MDM2-promoter luciferase reporter assay in HEK293T cells. Overexpression of HA-p53 significantly induced MDM2promoter luciferase activity, which was further enhanced by NSC697923 (Figure 3e). Moreover, $2 \mu \mathrm{M}$ of NSC697923 induced expression of p53-targeted gene p21 as well as the cleavage of caspase 3 in two p53 wild-type cell lines SH-SY5Y 
a
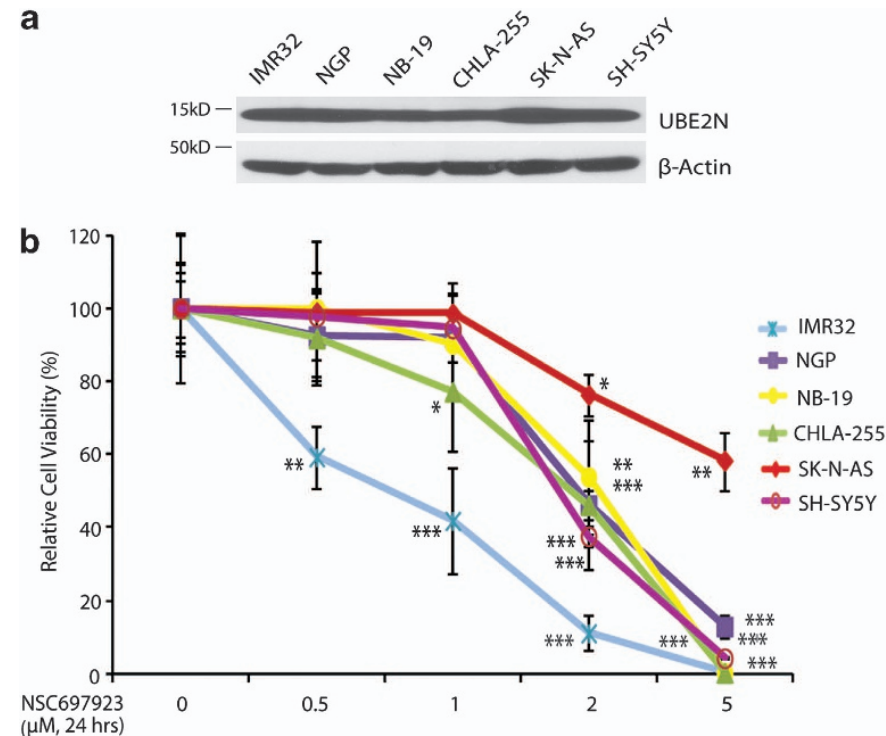

\section{NSC697923}

$(\mu \mathrm{M}, 24 \mathrm{hrs})$

IMR32
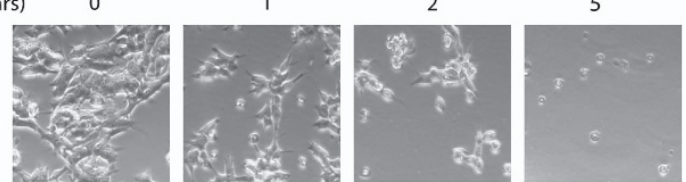

SH-SY5Y
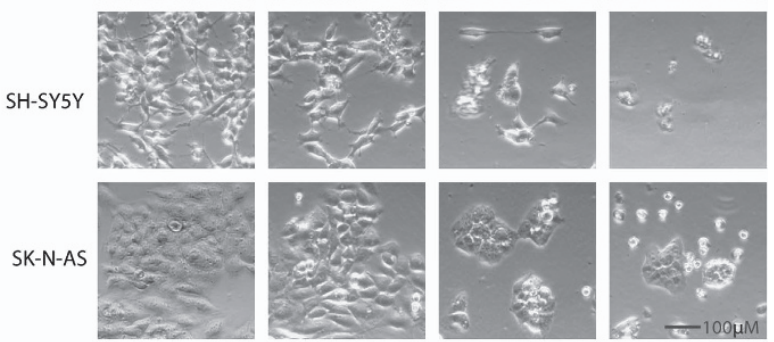
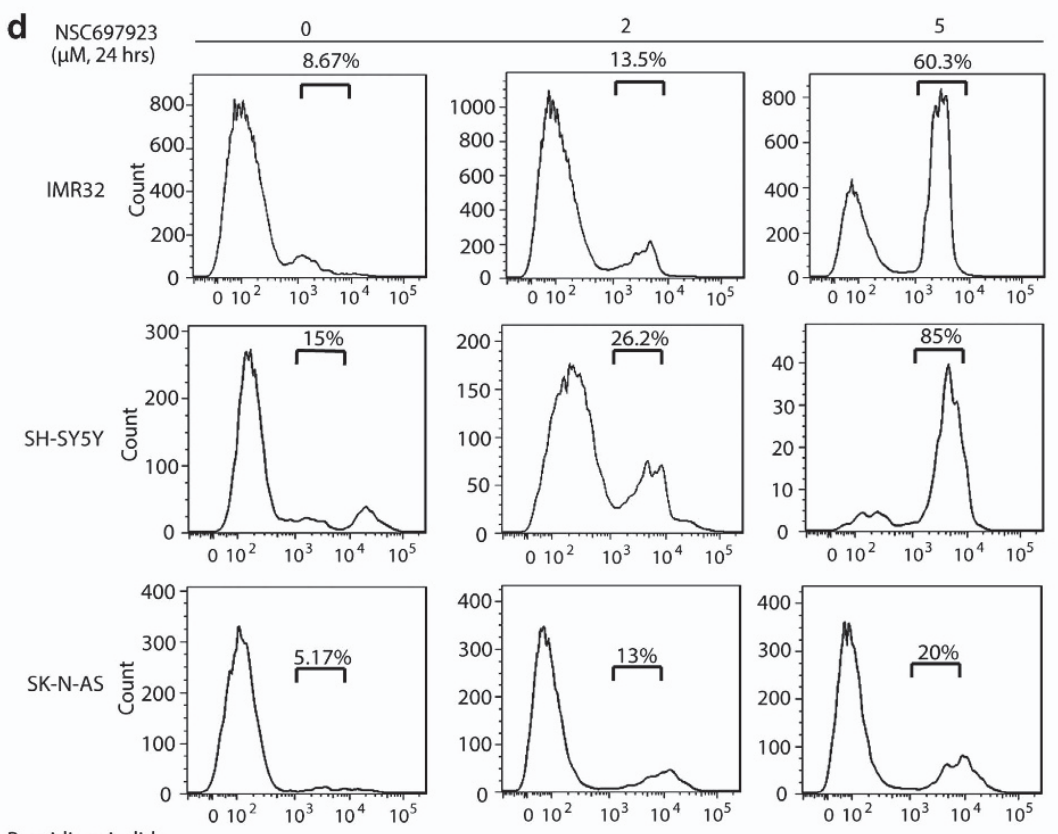

Figure 1 NSC697923 shows cytotoxic effect on NB cell lines. (a) A panel of six NB cell lines were lysed, subjected to SDS-PAGE and immunoblotted with UBE2N antibodies. Beta-actin was detected as a loading control. (b) Six NB cell lines were treated with the indicated concentrations of NSC697923 for $24 \mathrm{~h}$. Cell viability was then measured by adding $10 \mu \mathrm{l}$ of CCK-8 and reading the absorbance at $450 \mathrm{~nm}$. Data were represented as mean \pm S.D. $P$-values $<0.05\left({ }^{*}\right),<0.01\left(^{* *}\right)$, or $<0.001\left({ }^{* \star *}\right)$ were indicated. (c) IMR32, SH-SY5Y and SK-N-AS cells were treated with indicated concentrations of NSC697923 for $24 \mathrm{~h}$ and cell morphology was captured using optical microscope. (d) IMR32, SH-SY5Y, and SK-N-AS cells were first incubated with indicated concentrations of NSC697923 for $24 \mathrm{~h}$, stained by propidium iodide (PI) without fixing and then analyzed by flow cytometry. PI-positive cells were shown by percentage. Data from $\mathbf{a}$ are representative of two independent experiments. Data from $\mathbf{b}$ to $\mathbf{d}$ are representative of three independent experiments

and IMR32, but not in p53 mutant cell line SK-N-AS (Figure 3f). Together, our results indicate that NSC697923 induces apoptosis in 553 wild-type NB cell lines by promoting p53 nuclear translocation and activation.

Activation of JNK, but not p38, ERK, or NF- $\kappa \mathrm{B}$ is required for NSC697923-induced apoptosis in p53 mutant NB cell line. UBE2N inhibition also has a cytotoxic effect on p53 mutant SK-N-AS cell line, although less potent when compared with p53 wild-type NB cell lines, suggesting that NSC697923 also can induce cell death independent of p53. It is well recognized that UBE2N is critical for NF- $\kappa \mathrm{B}$ and MAPKs activation, and NSC697923 can suppress constitutive NF- $\kappa$ B activity in DLBCL cells. ${ }^{25}$ To better elucidate the potential mechanism of NSC697923-induced cell death in p53 mutant SK-N-AS cells, we first tested baseline activation of NF- $\kappa$ B and MAPKs pathways, including JNK, p38, and ERK in a panel of six NB cell lines. 

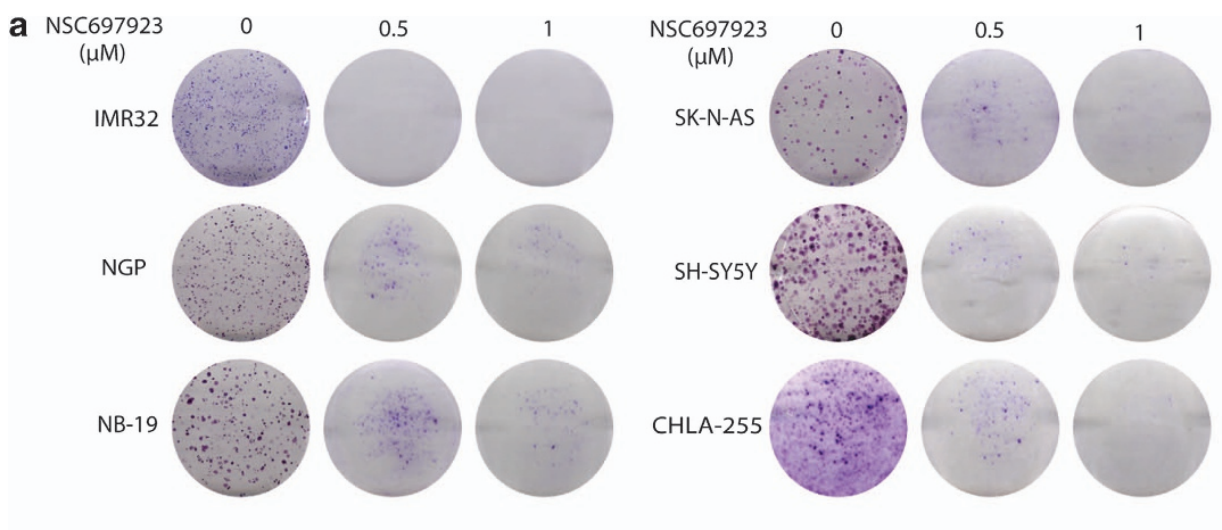

b
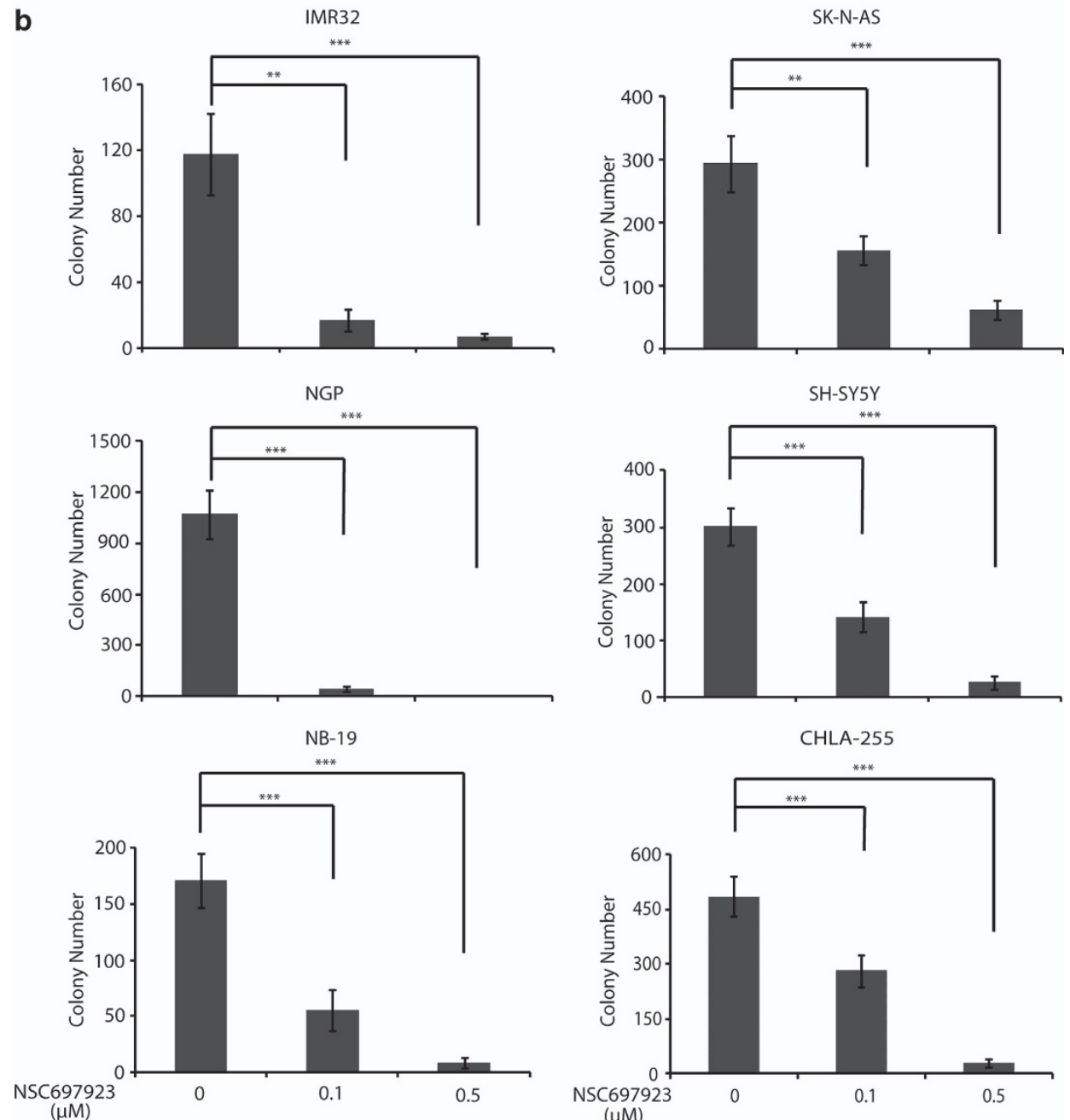

Figure 2 NSC697923 inhibits NB cells colony-formation ability. (a) A panel of six NB cell lines were seeded in six-well plates at $10^{2} /$ well, respectively, and allowed to grow for $24 \mathrm{~h}$. Cells were then incubated with indicated concentrations of NSC697923 and grown in RPMl 1640 medium for 2 weeks. The colonies produced were fixed, stained with crystal violet dye, and photographed. (b) A panel of six NB cell lines were seeded in six-well plates with NSC697923 and agar, and grown for 2 weeks. Cells were stained with MTT for $4 \mathrm{~h}$, pictures were taken and colonies were counted. Colony numbers were represented as mean \pm S.D. $P$-values $\left.<0.01{ }^{(* *}\right)$ or $<0.001{ }^{\left({ }^{* \star}\right)}$ were indicated. Data from $\mathbf{a}$ to $\mathbf{b}$ are representative of three independent experiments

Among these cell lines, only SK-N-AS showed activation of $\mathrm{NF}-\kappa \mathrm{B}$ pathway. All tested cell lines had different levels of JNK, p38, and ERK activation, while SK-N-AS had higher baseline levels of activation compared with the others (Figure 4a).
To determine the mechanism of NSC697923-induced apoptosis in p53 mutant NB cells, we treated SK-N-AS cells with increasing doses of NSC697923 to examine the effects of NSC697923 on NF- $k B$ and MAPKs activation. To our surprise, as the drug concentration increased, there was more 


\section{a}

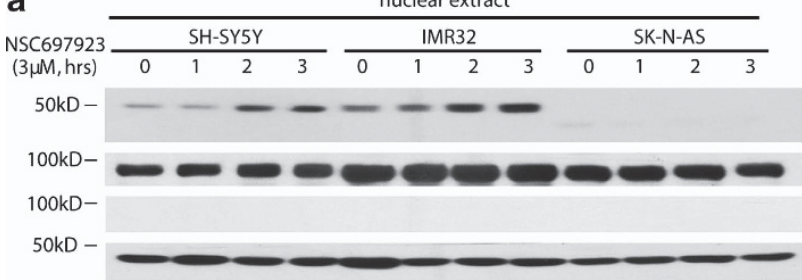

b

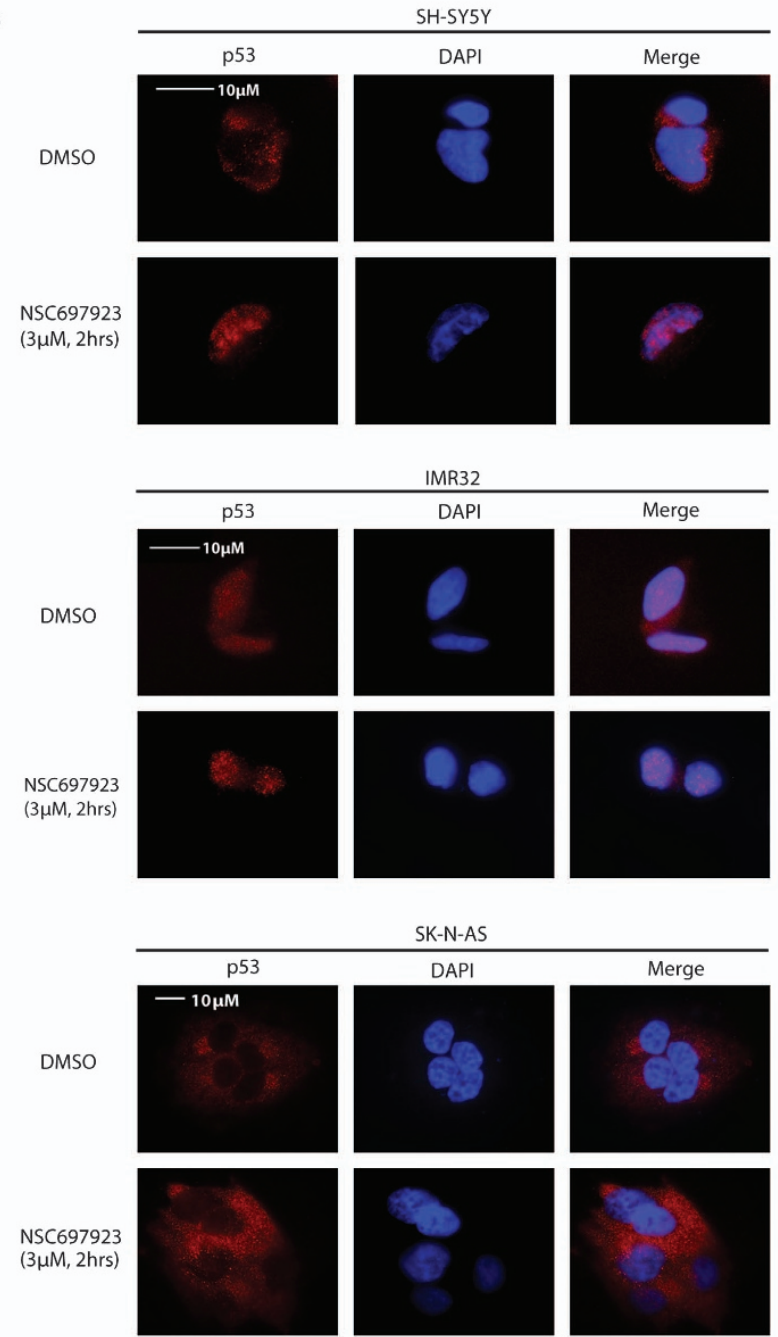

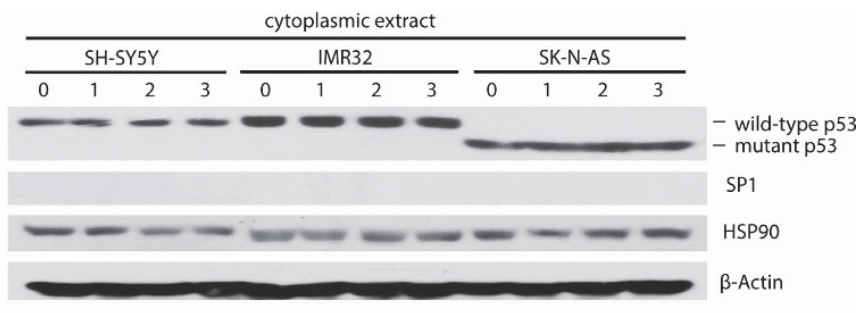

c

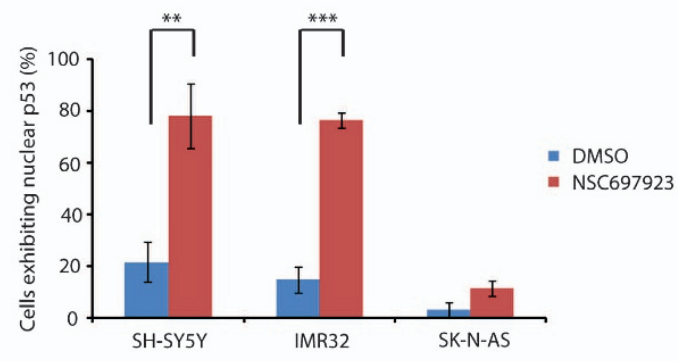

d

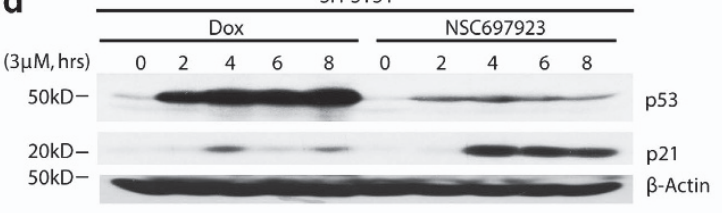

e

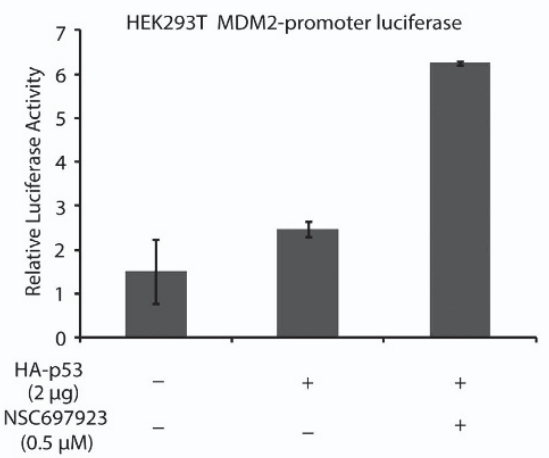

f

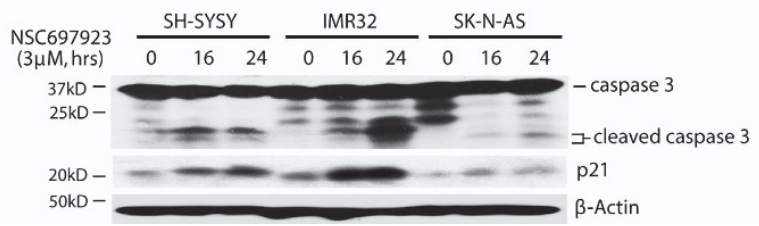

Figure 3 NSC697923 induces apoptosis by activation of p53 in p53 wild-type NB cells. (a) SH-SY5Y, IMR32, and SK-N-AS cells were treated with indicated concentrations of NSC697923 for different time courses, after which cytoplasmic and nuclear proteins were extracted, subjected to SDS-PAGE and immunoblotted with p53 antibodies. The purity of nuclear and cytoplasmic extracts was proved by anti-SP1 and anti-HSP90, respectively. (b and c) SH-SY5Y, IMR32, and SK-N-AS cells were incubated with or without $3 \mu \mathrm{M}$ of NSC697923 for $2 \mathrm{~h}$, cells were then fixed, incubated with anti-p53 antibodies, and then with Alexa Fluor 555 goat anti-mouse. Cell nuclei were stained with DAPI. Then images were acquired, and the number of cells exhibiting nuclear p53 before and after NSC697923 treatment was counted and represented as mean \pm S.D. $P$-values $<0.01\left(^{* *}\right)$ or $<0.001{ }^{* * *}$ ) were indicated. (d) SH-SY5Y cells were treated with $3 \mu \mathrm{M}$ of NSC697923 or Dox for the time courses as indicated and immunoblotted with p53 and p21 antibodies. Beta-actin was detected as a loading control. (e) HEK293T cells were co-transfected with MDM2 promoter-luciferase reporter plasmid and Renilla-luciferase control plasmid along with Topo-HA-p53 or Topo-vector plasmid. After $48 \mathrm{~h}$, cells were either left untreated or treated with $0.5 \mu \mathrm{M}$ of NSC697923 for $16 \mathrm{~h}$. The relative MDM2-luciferase activity was determined by dividing the firefly luciferase activity by Renilla luciferase activity. (f) SH-SY5Y, IMR32, and SK-N-AS cells were treated with $2 \mu \mathrm{M}$ of NSC697923 for the time courses as indicated and immunoblotted with caspase 3 and p21 antibodies. Beta-actin was detected as a loading control. Data from $\mathbf{a}$ and $\mathbf{f}$ are representative of three independent experiments. Data from $\mathbf{b}$ to $\mathbf{e}$ are representative of two independent experiments

degradation of $\mathrm{I}_{\kappa} \mathrm{B} \alpha$ (Figure $4 \mathrm{~b}$ ). Moreover, NSC697923 treatment also induced more phosphorylation of JNK, p38, and ERK in SK-N-AS (Figure 4b). To investigate which pathway contributes to NSC697923-induced NB cell death, we used specific inhibitors to individually block $\mathrm{NF}-\kappa \mathrm{B}$ or MAPKs pathways. The results showed that only the JNK-specific inhibitor, SP600125, protected SK-N-AS from NSC697923-induced cell death, whereas blockade of the $I_{\kappa} B$ 
a

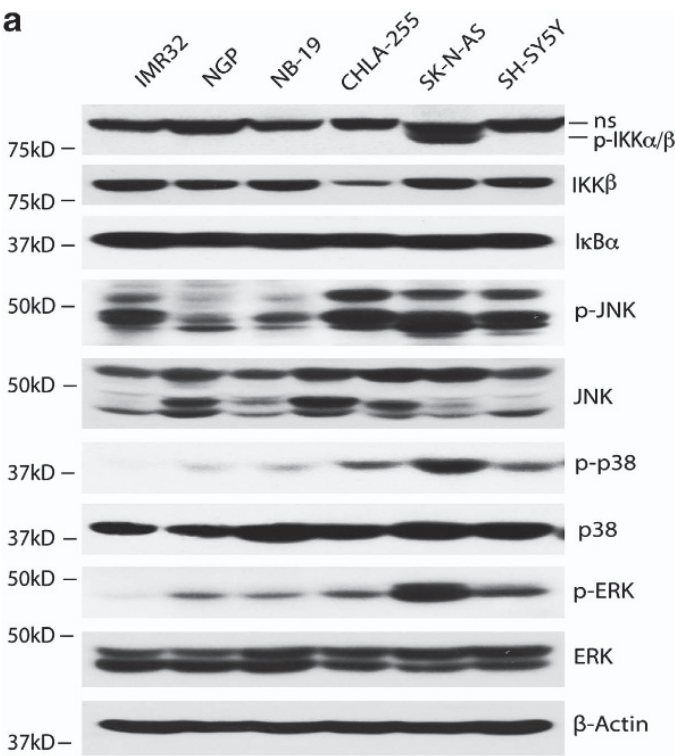

b

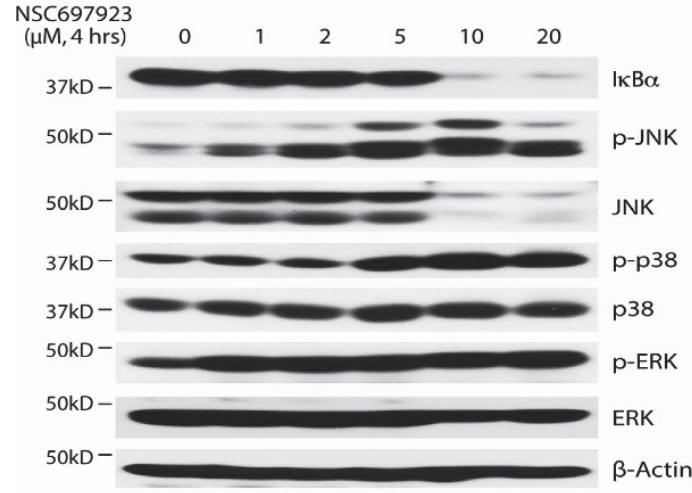

C

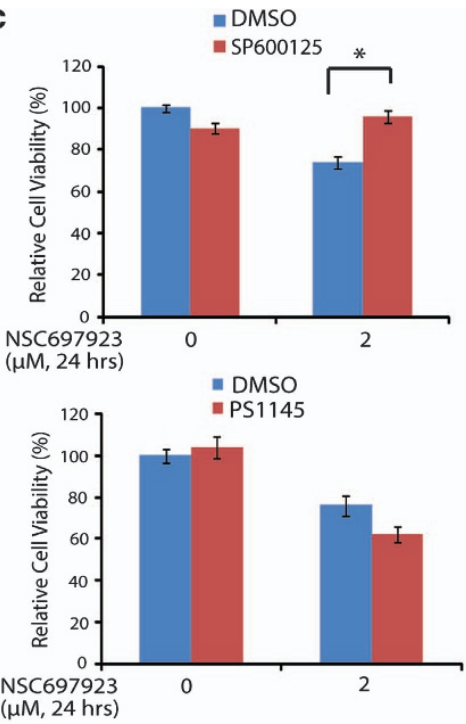

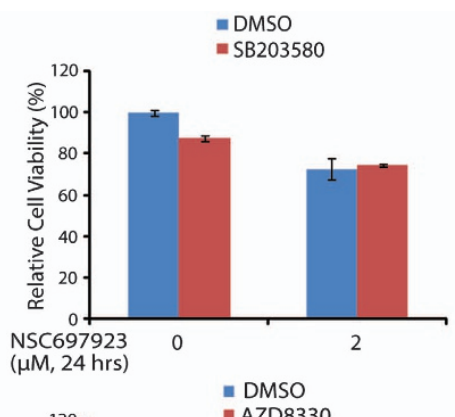

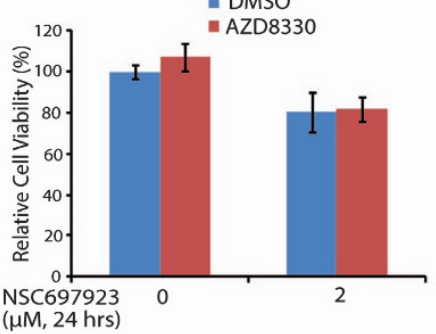

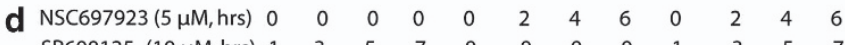
$\begin{array}{lllllllllllll}\mathrm{SP} 600125(10 \mu \mathrm{M}, \mathrm{hrs}) & 1 & 3 & 5 & 7 & 0 & 0 & 0 & 0 & 1 & 3 & 5 & 7\end{array}$

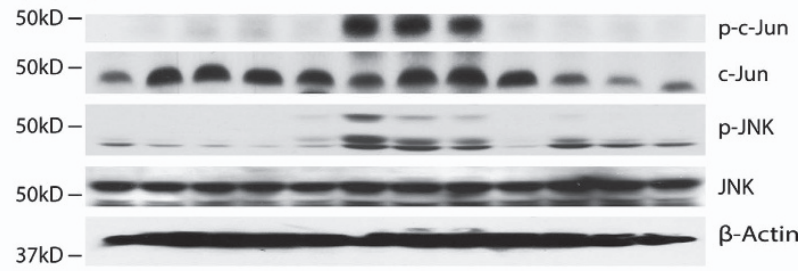

e

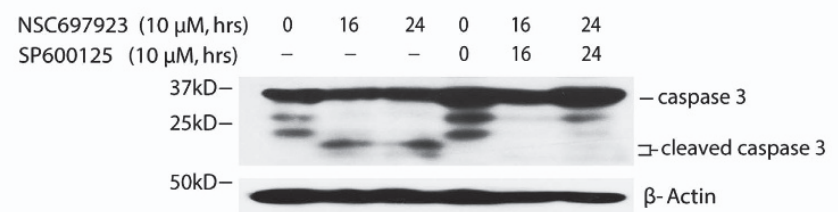

Figure 4 NSC697923 induces apoptosis through activation of JNK pathway in p53 mutant NB cells. (a) A panel of six NB cell lines were lysed, subjected to SDS-PAGE and immunoblotted with indicated antibodies. (b) SK-N-AS cells were treated with indicated concentrations of NSC697923 for $4 \mathrm{~h}$, lysed, subjected to SDS-PAGE and immunoblotted with indicated antibodies. (c) SK-N-AS cells were left untreated or treated with NSC697923 alone, specific pathway inhibitor alone (SP600125: JNK inhibitor; PS1145: IKK inhibitor; SB203580: p38 inhibitor; AZD8330: ERK inhibitor), or the combination of the two for $24 \mathrm{~h}$, then cell viability was measured by adding $10 \mu$ l of CCK-8 and reading the absorbance at $450 \mathrm{~nm}$. Data are represented as mean \pm S.D. P-value $<0.05\left(^{*}\right)$ was indicated. (d and e) SK-N-AS cells were treated with NSC697923 alone, SP600125 alone, or the combination of the two for the time courses as indicated. Cells were lysed, subjected to SDS-PAGE, and immunoblotted with indicated antibodies. Beta-actin was detected as a loading control. Data from $\mathbf{a}, \mathbf{c}$, and $\mathbf{e}$ are representative of three independent experiments. Data from $\mathbf{b}$ and $\mathbf{d}$ are representative of two independent experiments

kinase (IKK), p38, or ERK had little or no effect (Figure 4c). In order to assess SP600125's ability to block JNK pathway, we performed western blotting with SK-N-AS cell line. As expected, NSC697923 treatment induced strong phosphorylation of c-Jun and JNK, which was significantly blocked when cells were coincubated with SP600125 (Figure 4d). Furthermore, SP600125 caused significant reduction of NSC697923-induced caspase 3 cleavage (Figure 4e). Collectively, these studies provide evidence that NSC697923 can also induce apoptosis in p53 mutant NB cells by activation of JNK-mediated apoptotic pathway.

NSC697923 has a greater cytotoxic potency on chemoresistant LA-N-6 cells than Dox and VP16. In order to evaluate the potency of NSC697923 to induce apoptosis in a chemoresistant NB cell line, LA-N-6, we used chemotherapy drugs Dox and VP16 as comparison. As shown in Figure 5a, $24 \mathrm{~h}$ of incubation with NSC697923 resulted in a dosedependent reduction in cell viability in LA-N-6 cells, whereas Dox and VP16 treatments at the same dose had much less significant effect. Cell morphological images further support this result (Supplementary Figure 2a). In addition, propidium iodide $(\mathrm{PI})$ staining showed a greater increase in the number of apoptotic LA-N-6 cells after NSC697923 exposure when compared with Dox and VP16 at the same dose (Figure 5b). We then tested whether NSC697923 could suppress colony formation of LA-N-6 cells. Consistent with the results from other NB cell lines, both anchorage-independent and dependent colony formation of LA-N-6 cells was inhibited by NSC697923 (Figures 5c and d and Supplementary Figure 2b). 
To further analyze if cell death of LA-N-6, which bears wildtype $\mathrm{p53}$, was caused by the same mechanisms as the other NB cell lines, we first detected cleaved caspase 3 and p21 levels after incubation with NSC697923 as well as Dox and VP16. Indeed, stronger induction of cleaved caspase 3 and p21 protein was observed when cells were treated with NSC697923 compared with Dox and VP16 treatment at the same dose (Figure 5e). We also evaluated the activity of JNK pathway after NSC697923, Dox, and VP16 treatment. Western blotting analysis of phospho-c-Jun and JNK suggested that NSC697923, but not Dox or VP16, also triggered a stronger activation of JNK signaling (Figure 5f). NSC697923induced cell death was partially rescued by blockade of JNK activity with JNK inhibitor SP600125 (Figure 5g). Our data indicate that NSC697923 has a stronger cytotoxic potency on the LA-N-6 cell line than the conventional chemotherapeutic drugs Dox and VP16 by functioning through both p53 and JNK pathways.

As monotherapies are rarely effective in the treatment of high-risk NB due to chemoresistance, we evaluated the synergistic effect of NSC697923 in combination with Dox and VP16 using LA-N-6 cells. Cell viability assay showed that NSC697923 significantly enhanced the cytotoxicity of both drugs in chemoresistant LA-N-6 cells (Figures $5 \mathrm{~h}$ and i). Together, our results suggest that NSC697923 not only efficiently induces cell death but also enhances cytotoxicity effect of chemotherapeutic drugs on chemoresistant NB cells.

NSC697923 suppresses NB tumor growth in vivo. Given the potent cytotoxic effect of NSC697923 on NB cells in vitro, we proceeded to evaluate its efficacy on inhibiting NB tumor growth in an orthotopic NB mouse model. Two cell lines SH-SY5Y and NGP with stable luciferase gene expression were used in this set of in vivo experiments. At the end of NSC697923 treatment, the xenograft tumors from both control and treatment groups were harvested and weighed. As expected, we observed significant tumor regression in NSC697923 treatment group of both SH-SY5Y and NGP xenografts (Figures $6 a$ and b). The response of NB xenografts to NSC697923 demonstrates its potent antitumor efficacy as a single agent in vivo.

\section{Discussion}

NB is the most common extracranial solid tumor of childhood and accounts for $\sim 15 \%$ of cancer-related deaths in children. $^{26}$ Currently, there are no efficient therapeutic methods to improve patient outcomes in clinic. This highlights the urgent need for the identification of novel therapeutic targets. Unlike many other human malignancies, almost all NBs carry wild-type but non-functional p53 due to its abnormal sequestration in the cytoplasm. ${ }^{13,27}$ Therefore, we put our current research efforts in reactivating p53 signaling pathway in NB. Here, we have found that NSC697923, a smallmolecule inhibitor of UBE2N, efficiently induces p53 nuclear translocation and promotes p53-mediated apoptosis in multiple p53 wild-type NB cell lines. NSC697923 can also induce apoptosis with less potency in p53 mutant NB cells by activating JNK-mediated apoptotic pathway. More remarkably, NSC697923 significantly induces cell death in chemoresistant NB cells and sufficiently inhibits NB growth in vivo. Collectively, our preclinical results indicate that UBE2N inhibition by small-molecule inhibitors is a novel therapeutic strategy not only for p53 wild-type but also for p53 mutant NB.

The E2-conjugating enzyme UBE2N is known to mediate Lysine 63-specific protein ubiquitination and its role in immune cells has been extensively studied. Genetic studies in mice by different groups have confirmed that UBE2N is critical for NF- $\kappa$ B and MAPKs activation in most immune cells. ${ }^{19,28}$ This is consistent with the study showing that UBE2N inhibitor, NSC697923, inhibits proliferation and survival of DLBCL cells by inhibiting constitutive NF- $\kappa$ B activation. ${ }^{25}$ However, the role of UBE2N in non-immune cells and its contribution to solid tumor development are largely unknown. As UBE2N is also involved in the DNA damage response pathway, it is likely that UBE2N might play a critical role in NB tumorigenesis and chemotherapy response. Here, we found inhibition of UBE2N function by NSC697923 causes NB cell death by inducing p53 as well as JNK activation in NB cells, suggesting that UBE2N is required for NB survival. This result is supported by a recent study showing that genetic deletion of UBE2N in keratinocytes resulted in apoptosis of keratinocytes. ${ }^{29}$ However, it is still unclear why and how UBE2N inhibition by NSC697923 can activate NF- $\kappa$ B and MAPKs in NB cells and the underlying molecular mechanisms need to be further pursued.

In addition to NSC697923, several other UBE2N inhibitors have also been reported including Leucettamol $A$, isolated from the marine sponge Leucetta aff. microrhaphis, which inhibits the formation of UBE2N-Uev1A complex; two new dimeric sterols, manadosterols $A$ and $B$, which have more potent inhibitory activities against UBE2N-Uev1A than Leucettamol $A\left(\mathrm{IC}_{50}\right.$ values of $0.09 \mu \mathrm{M}$ and 0.13 versus $106 \mu \mathrm{M})$; and a sub-micromolar $\left(\mathrm{IC}_{50}=781 \mathrm{nM}\right)$ inhibitor of UBE2N, ML307. ${ }^{22-24}$ However, none of the above inhibitors have been tested for antitumor activity in vivo. Here, we provide the first evidence that an UBE2N inhibitor, NSC697923, is a potent antitumor agent in vivo by activating p53- and JNK-mediated apoptotic pathways.

The high frequency of alterations in p53 signaling in cancer makes this pathway a favorable drug target in the development of small-molecular inhibitors and many of them have successfully reached the stage of clinical trials. Those compounds are mainly divided into two categories: (1) targeting mutant p53 to restore its native conformation and transcriptional activity; (2) targeting wild-type p53 and liberating it from an inhibitory p53-MDM2 complex. ${ }^{30}$ PRIMA-1 and its optimized derivative PRIMA-1 ${ }^{\mathrm{MET}}$ are proved to specifically inhibit p53 mutant tumor growth by restoring the function of mutant p53. ${ }^{31,32}$ Nutlin-3 and the spiro-oxindole MI-43 are two representative drugs that act as MDM2 antagonists to activate wild-type p53 by disrupting p53-Mdm2 interaction. $^{33,34}$ P22077, a recently identified USP7 inhibitor, promotes MDM2 degradation and subsequently stabilizes p53 to induce p53-mediated apoptosis. ${ }^{35}$ Despite the fact that impressive breakthroughs have been made in discovering p53-targeting compound, very few small-molecule inhibitors have been reported to promote p53 nuclear accumulation and activation. $^{36,37}$ Here we provide convincing evidence to show 
that NSC697923 can sufficiently promote p53 nuclear translocation and subsequently induce p53-mediated apoptosis in NB cells.

a

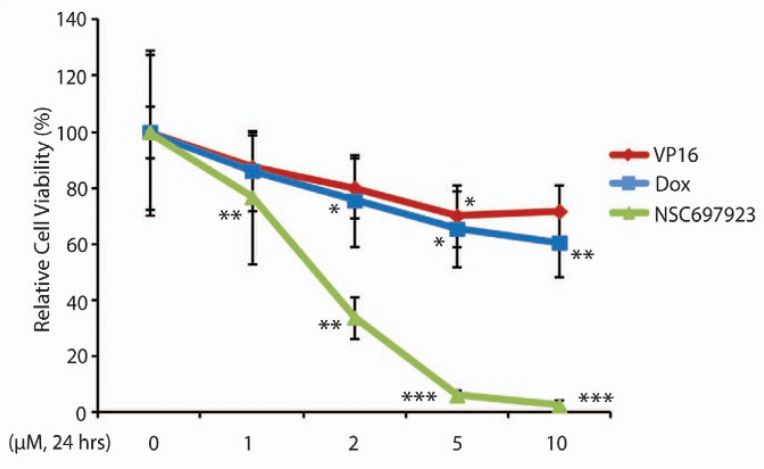

C

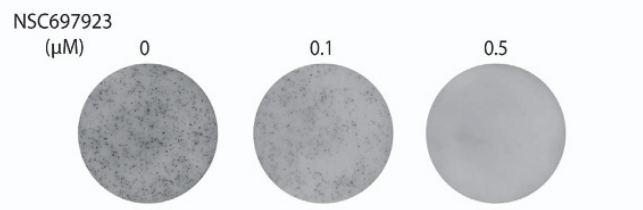

d

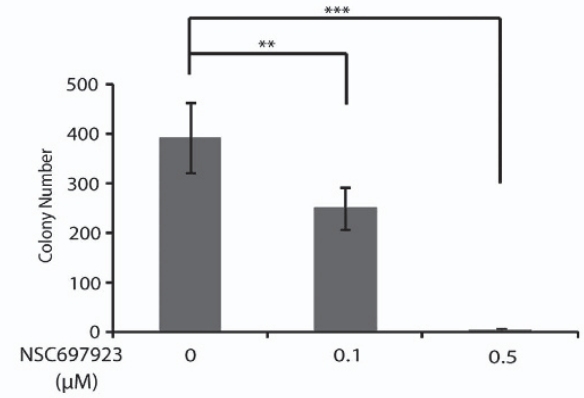

f

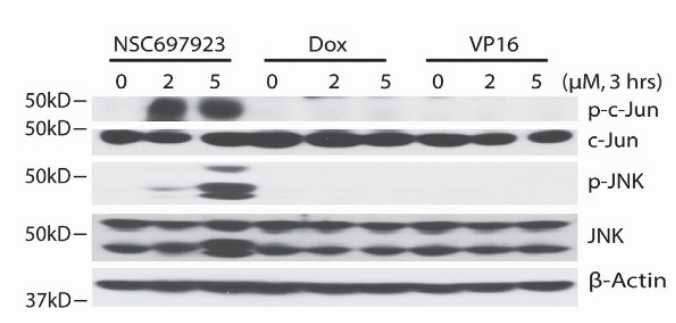

h

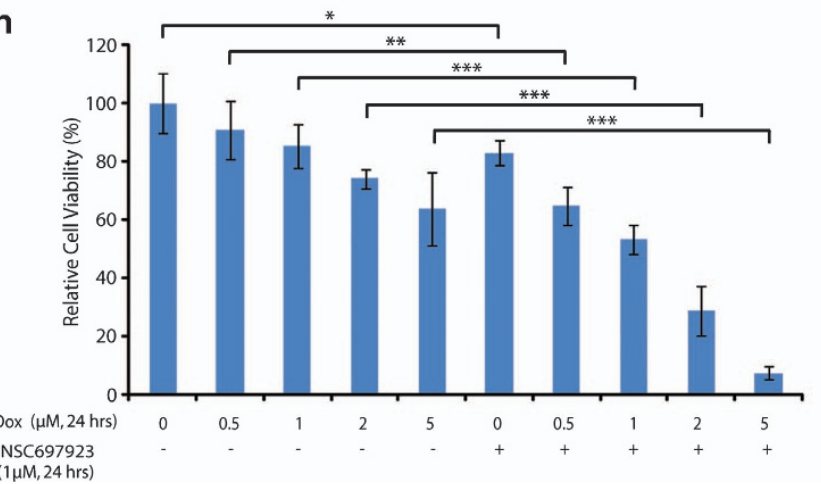

JNK is an important MAPK and its role in cancer is controversial. In different biological conditions and cancer types, JNK either support cell-survival or induce apoptosis.

b
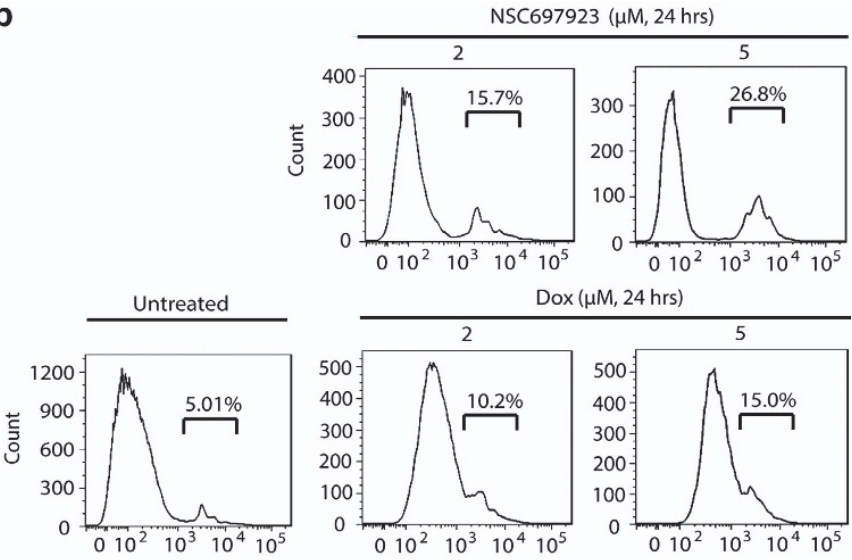

$\operatorname{VP} 16(\mu \mathrm{M}, 24 \mathrm{hrs})$

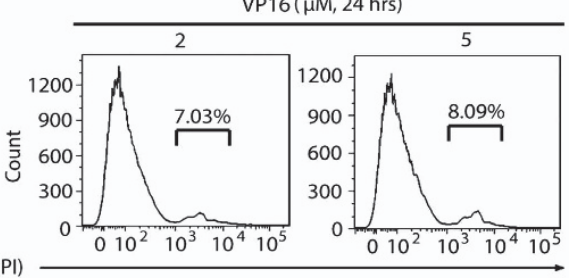

Propidium iodide (PI)
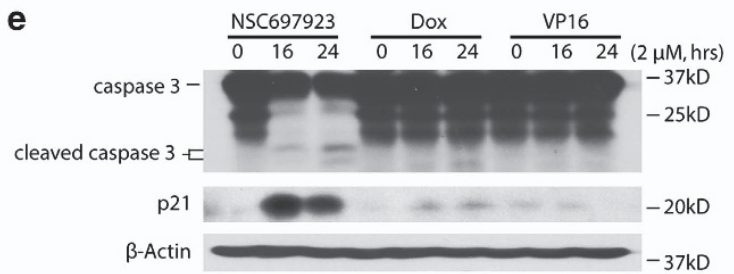

g

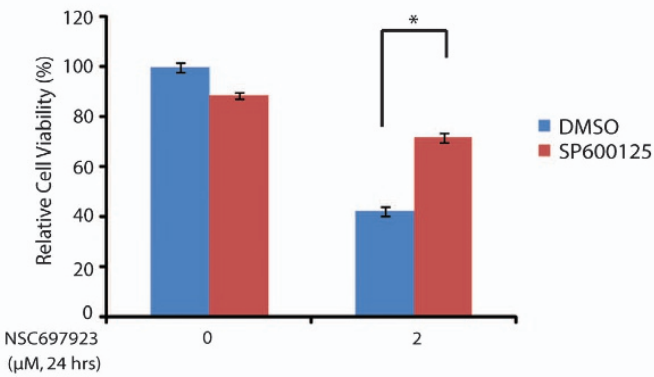

i

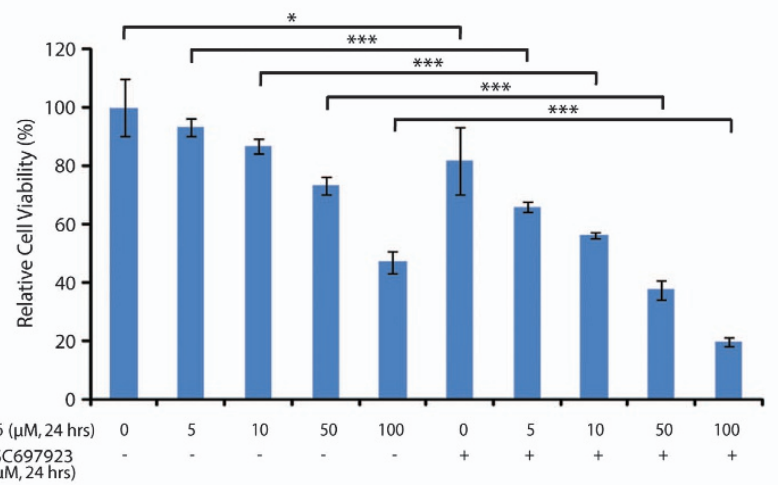




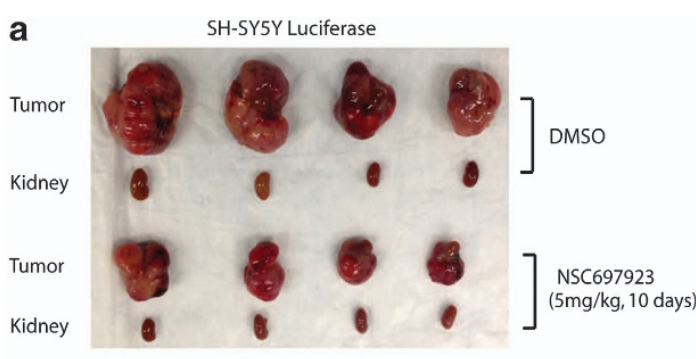

b

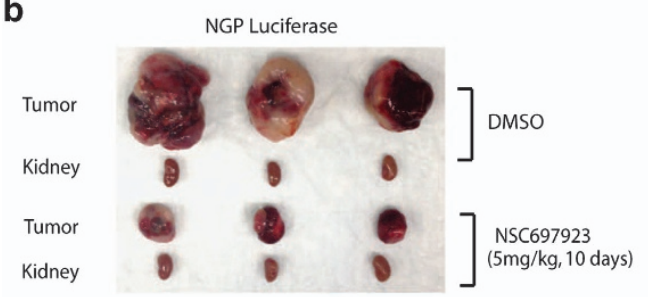

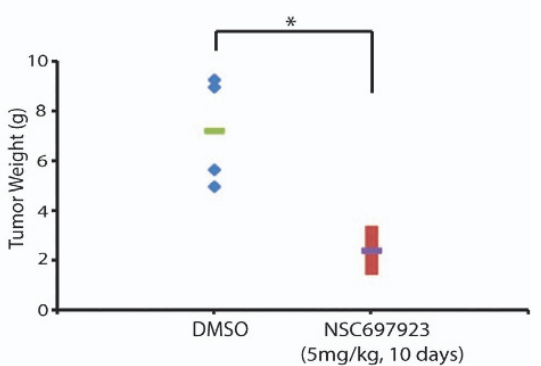

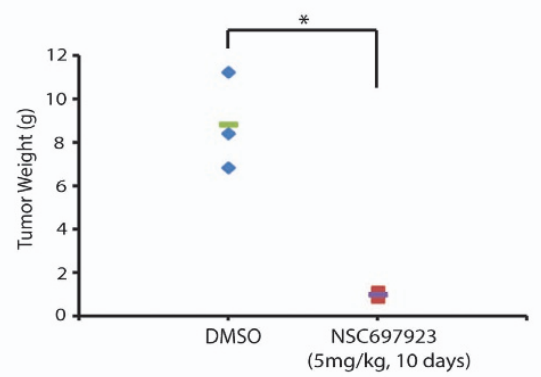

C

Neuroblastoma Cells

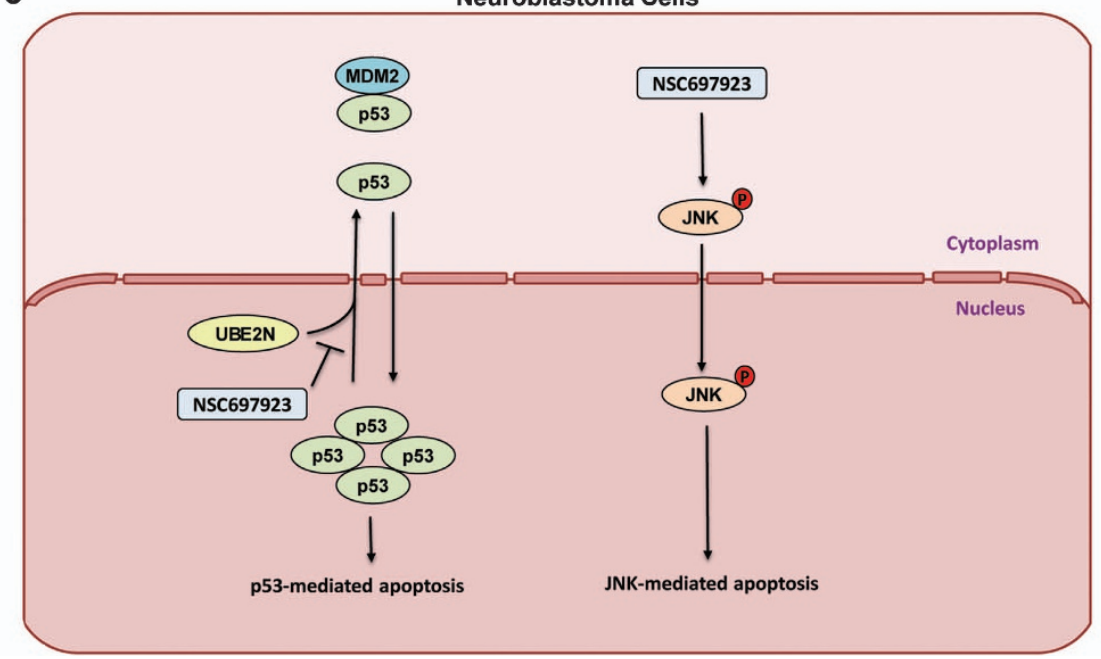

Figure 6 In vivo efficacy of NSC697923 on human NB xenografts. (a) At the end of the indicated treatment schedules, SH-SY5Y xenografted tumors and tumor weights from control $(N=4)$ and treatment groups $(N=4)$ were presented. (b) At the end of the indicated treatment schedules, NGP xenografted tumors and tumor weights from control $(N=3)$ and treatment groups $(N=3)$ were presented. $P$-value $<0.05\left(^{*}\right)$ was indicated. (c) The working model for UBE2N inhibitor NSC697923-mediated NB cell apoptosis. In p53 wild-type NB cells, UBE2N inhibition blocks cytoplasm transportation of p53, increases its nuclear accumulation, and leads to p53-mediated apoptosis. While in p53 mutant NB cells, NSC697923 induces JNK phosphorylation and activates JNK-mediated apoptosis. Data from $\mathbf{a}$ and $\mathbf{b}$ are representative of two independent experiments

Figure 5 NSC697923 has stronger cytotoxic effects than Dox and VP16 on chemoresistant NB cell line LA-N-6. (a) LA-N-6 cells were treated with indicated concentrations of NSC697923, Dox, or VP16 for $24 \mathrm{~h}$. Cell viability was then measured by adding $10 \mu \mathrm{l}$ of CCK-8 and reading the absorbance at $450 \mathrm{~nm}$. Data were represented as mean \pm S.D. $P$-values $\left.<0.05\left({ }^{*}\right),<0.01{ }^{* \star}\right)$, or $<0.001\left(^{* \star *}\right)$ were indicated. (b) LA-N-6 cells were first incubated with the indicated concentrations of NSC697923, Dox, or VP16 for $24 \mathrm{~h}$, stained by propidium iodide (PI) without fixing and then analyzed by flow cytometry. PI-positive cells were shown by percentage. (c and d) LA-N-6 cells were seeded in six-well plates with NSC697923 and agar, and grown for 2 weeks, then stained with MTT for $4 \mathrm{~h}$, pictures were taken and colonies were counted. Colony numbers were represented as mean \pm S.D. P-values $\left.<0.01{ }^{* *}\right)$ or $<0.001{ }^{\left({ }^{* *}\right)}$ were indicated. (e and f) LA-N-6 cells were treated with indicated concentrations of NSC697923, Dox, and VP16 for varying time courses, lysed, subjected to SDS-PAGE and immunoblotted with indicated antibodies. Beta-actin was detected as a loading control. (g) LA-N-6 cells were left untreated or treated with NSC697923 alone, JNK inhibitor SP600125 alone, or the combination of the two for $24 \mathrm{~h}$, then cell viability was then measured by adding $10 \mu \mathrm{l}$ of CCK-8 and reading the absorbance at $450 \mathrm{~nm}$. Data were represented as mean \pm S.D. P-value $<0.05\left({ }^{*}\right)$ was indicated. (h and i) LA-N-6 cells were treated with Dox or VP16 at the indicated concentrations with or without NSC697923 for $24 \mathrm{~h}$. Then cell viability was then measured by adding $10 \mu \mathrm{l}$ of CCK-8 and reading the absorbance at $450 \mathrm{~nm}$. Data were represented as mean \pm S.D. $P$-values $<0.05\left(^{(*)},<0.01{ }^{(* *}\right)$, or $<0.001\left(^{* \star *}\right)$ were indicated. Data from $\mathbf{a}$ to $\mathbf{e}$ and $\mathbf{h}$ to $\boldsymbol{i}$ are representative of three independent experiments. Data from $\mathbf{f}$ and $\mathbf{g}$ are representative of two independent experiments 
A recent study has demonstrated that JNK and p38 MAPK pathways, but not ERK pathway might serve as death signals in CPF-induced neuronal apoptosis in SH-SY5Y cell line. ${ }^{38}$ Consistent with this report, we found JNK inhibitor, SP600125, can efficiently rescue NSC697923-induced cell death in p53 mutant NB cell line SK-N-AS. SK-N-AS cells have basal JNK activation, which is insufficient to induce cell death, whereas NSC697923 is able to induce a much stronger JNK activation, which is sufficient to promote JNK-mediated cell death in this cell line. Thus, it seems that the magnitude of JNK activation is critical for its role in cell death induction in NB cells.

Despite recent progress in therapy, $50-60 \%$ of patients with high-risk NB still relapse after initial response to treatment, at which point there are no efficient salvage treatment regimens. ${ }^{39}$ Therefore, acquired resistance to current chemotherapy treatment in NB is an urgent and clinically relevant problem that needs to be addressed. It is well recognized that targeting one pathway in cancer cells is often accompanied with drug resistance. One significant feature of NSC697923 as a therapeutic drug is that it promotes NB cell death by activating two pathways. This suggests that NSC697923 may be used to overcome chemoresistance. This is supported by our observation that NSC697923 exhibited a much stronger cytotoxic effect in chemoresistant LA-N-6 cells compared with traditional chemotherapy drugs Dox and VP16, as well as the fact that it has synergistic effect with those two drugs.

Here, we propose a working model regarding how UBE2N inhibitor NSC697923 induces cell death in NB cells: In p53 wild-type NB cells, UBE2N inhibition blocks cytoplasm transportation of p53, increases its nuclear accumulation, and leads to p53-mediated apoptosis. While in p53 mutant NB cells, NSC697923 induces JNK phosphorylation and activates JNK-mediated apoptosis (Figure $6 \mathrm{c}$ ). In conclusion, we provide the first preclinical evidence showing the potential utility of UBE2N inhibitors in the treatment of NB. Given the fact that many relapse NBs are refractory to traditional chemotherapy, NSC697923 may serve as an ideal drug to improve patient outcomes by activating both p53- and JNK-mediated apoptotic pathways.

\begin{abstract}
Materials and Methods
Antibodies and reagents. UBE2N inhibitor NSC697923 (662107) was obtained from Calbiochem (EMD Millipore, Billerica, MA, USA). Dox (D1515), VP16 (E1383) and anti- $\beta$-actin (A2228) antibodies were obtained from Sigma (Sigma-Aldrich Corp, St. Louis, MO, USA). Anti-UBE2N (371100) was obtained from Invitrogen (Invitrogen Corporation, Carlsbad, CA, USA). Anti-caspase 3 (9662), anti-phospho-IKK $\alpha / \beta$ (2078), anti-IKK $\beta$ (2684), anti-I $\kappa \mathrm{B} \alpha$ (9242), antiphospho-JNK (9251), anti-JNK (9252), anti-phospho-p38 (9211), anti-p38 (9212), anti-phospho-ERK (9106), anti-ERK (9102), anti-Mouse (7076), and anti-Rabbit (7074) antibodies were obtained from Cell Signaling Technology (Cell Signaling Technology, Danvers, MA, USA). Anti-p53 (sc-126), anti-p21 (sc-53870), antiphospho-c-Jun (sc-822), anti-c-Jun (sc-44), anti-SP1 (sc-59), and anti-HSP90 (sc-7947) antibodies were obtained from Santa Cruz (Santa Cruz Biotechnology, Dallas, TX, USA).
\end{abstract}

Cell lines and cell culture. Human NB cell lines with MYCN amplification (IMR-32, NGP and NB-19) and without (CHLA-255, SK-N-AS and SH-SY5Y) were maintained in RPMI 1640 medium (Cellgro, Manassas, VA, USA) supplemented with $10 \%(\mathrm{~V} / \mathrm{v})$ heat-inactivated fetal bovine serum (FBS; SAFC Biosciences, Lenexa, KS, USA), $100 \mathrm{units} / \mathrm{ml}$ penicillin, and $100 \mu \mathrm{g} / \mathrm{ml}$ streptomycin. Chemoresistant NB cell line LA-N-6 was maintained in RPMl 1640 medium containing 20\% (v/v) heat-inactivated FBS, 100 units $/ \mathrm{ml}$ penicillin, and $100 \mu \mathrm{g} / \mathrm{ml}$ streptomycin. HEK293T cell line was grown in Dulbecco's modified Eagle's medium (Cellgro, Manassas, VA, USA) supplemented with 10\% (v/v) FBS, $100 \mathrm{units} / \mathrm{ml}$ penicillin, and $100 \mu \mathrm{g} / \mathrm{ml}$ streptomycin. All cell lines were maintained in a humidified incubator containing $5 \% \mathrm{CO}_{2}$ at $37^{\circ} \mathrm{C}$.

Cell viability assay. Cells were seeded and grown in 96-well plates at $10^{4} /$ well overnight. Medium was replaced with medium containing drugs at varying concentrations, and the cells were then incubated at $37^{\circ} \mathrm{C}$ for $24 \mathrm{~h}$ before $10 \mu \mathrm{l}$ of CCK-8 (Dojindo Laboratories, Rockville, MA, USA) was added to each well. After $1 \mathrm{~h}$ of incubation, the absorbance was measured at $450 \mathrm{~nm}$ using a microplate reader. The experiment was performed in sextuplicate. Background reading of medium was used to normalize the result.

Cell imaging. NB cell lines were seeded in 12-well plates at a density of $10^{5} /$ well. After $24 \mathrm{~h}$ of treatment with NSC697923 at various concentrations, cell morphology was photographed using optical microscope.

PI staining assay. The experiment was performed as described previously. ${ }^{40}$ Briefly, NB cell lines were seeded in $10 \mathrm{~cm}$ dishes and treated with increasing concentrations of NSC697923 for $24 \mathrm{~h}$. Cells were then washed with $1 \times$ cold PBS twice, and resuspended at a density of $10^{6}$ cells $/ \mathrm{ml}$ in $1 \times$ binding buffer (51-66121E; BD Biosciences, San Jose, CA, USA). Then $100 \mu$ l of non-fixed cell suspension was transfered into a new tube and $5 \mu \mathrm{l}$ of PI staining solution (51-66211E; BD Biosciences) was added. Tubes were gently vortexed and incubated for $15 \mathrm{~min}$ at $\mathrm{RT}\left(25^{\circ} \mathrm{C}\right)$ in the dark. After adding additional $400 \mu \mathrm{l}$ of $1 \times$ binding buffer, the samples were analyzed by flow cytometry within $1 \mathrm{~h}$. As viable cells with intact membranes exclude PI, only the membranes of dead cells are permeable to $\mathrm{Pl}$. Unstained cells were used as a negative control.

Colony-formation assay. For clonogenic assay, cells were seeded in sixwell plates at $10^{2} /$ well. After $24 \mathrm{~h}$ of incubation, cells were treated with different concentrations of NSC697923 and allowed to grow for 2 weeks. At 2 weeks, the colonies produced were fixed with methanol and stained with $0.05 \%$ crystal violet dye for $10 \mathrm{~min}$. The plates were photographed.

For soft agar assay, a $5 \%(\mathrm{w} / \mathrm{v})$ base agar was prepared by melting the agar (214220; Difco Laboratories, Detroit, MI, USA) in distilled water, autoclaving for $30 \mathrm{~min}$ and cooling it to $56^{\circ} \mathrm{C}$ in a water bath. The $5 \%$ agar was mixed with RPMl 1640 (with 10\% FBS) for a final concentration of $0.5 \%$. The bottom layer was formed using $2 \mathrm{ml}$ of this $0.5 \%$ agar. The top layer was made with $1.5 \mathrm{ml}$ of $0.3 \%$ agar containing $3 \times 10^{4}$ cells/well along with different concentrations of NSC697923. Cells were grown at $37^{\circ} \mathrm{C}$ for 2 weeks and then stained with $500 \mu \mathrm{l}$ of $5 \mathrm{mg} / \mathrm{ml}$ Thiazolyl Blue Tetrazolium Bromide (MTT, M5655, Sigma). After $4 \mathrm{~h}$ of incubation, pictures were taken and colonies were counted using the microscope.

Western blotting assay. After each treatment, cells were washed twice with ice-cold $1 \times$ PBS and harvested in RIPA buffer $(50 \mathrm{mM}$ Tris- $\mathrm{HCl}$ at $\mathrm{pH} 7.4$, $150 \mathrm{mM} \mathrm{NaCl}, 1 \mathrm{mM}$ EDTA, $1 \%$ NP-40, 0.25\% sodium deoxycholate, $1 \mathrm{mM}$ phenylmethylsulfonyl fluoride, $1 \mathrm{mM}$ benzamidine, $10 \mu \mathrm{g} / \mathrm{ml}$ leupeptin, $1 \mathrm{mM}$ dithiothreitol, $50 \mathrm{mM}$ sodium fluoride, $0.1 \mathrm{mM}$ sodium orthovanadate, and phosphatase inhibitor cocktail 2 and 3 (p5726 and p0044, Sigma)), and then lysed at $4{ }^{\circ} \mathrm{C}$ for $20 \mathrm{~min}$. The lysed cells were centrifuged at 13000 r.p.m. for $15 \mathrm{~min}$, and the supernatants were used as cell lysates. Protein concentrations were measured using Bradford reagent (Bio-Rad Laboratories, Hercules, CA, USA). Lysates were mixed $3: 1(\mathrm{v} / \mathrm{v})$ with $4 \times$ loading buffer and heated at $100^{\circ} \mathrm{C}$ for $5 \mathrm{~min}$. Samples were then subjected to SDS-polyacrylamide gel electrophoresis (PAGE), transferred to polyvinylidence fluoride membranes (Bio-Rad), blocked with $5 \%$ milk or bovine serum albumin (BSA) for $1 \mathrm{~h}$ at RT and probed with appropriate dilutions of primary antibodies overnight at $4^{\circ} \mathrm{C}$. Membranes were then incubated with anti-mouse or rabbit $\operatorname{lgG}$ conjugated with horseradishperoxidase at $R T$ for $1 \mathrm{~h}$. The membranes were visualized by the ECL-Plus Western Detection System (GE Health Care, Buckinghamshire, UK).

Extraction of cytoplasmic and nuclear proteins. SH-SY5Y, IMR32, and SK-N-AS cells were seeded in $10 \mathrm{~cm}$ dishes and allowed to grow for $24 \mathrm{~h}$, after treated with $3 \mu \mathrm{M}$ of NSC697923 for different time courses, cells were washed with ice-cold $1 \times x$ PBS twice, harvested in hypotonic buffer $(10 \mathrm{mM}$ HEPES at pH 7.9, $10 \mathrm{mM} \mathrm{KCl,} 0.1 \mathrm{mM}$ EDTA, $1 \mathrm{mM}$ phenylmethylsulfonyl fluoride, $1 \mathrm{mM}$ benzamidine, $10 \mu \mathrm{g} / \mathrm{ml}$ leupeptin, $1 \mathrm{mM}$ dithiothreitol, $50 \mathrm{mM}$ sodium 
fluoride, $0.1 \mathrm{mM}$ sodium orthovanadate), and lysed at $4{ }^{\circ} \mathrm{C}$ for $15 \mathrm{~min}$. Samples were then centrifuged for $15 \mathrm{~min}$ at 13000 r.p.m., the supernatants were collected and used as cytoplasmic extract. To obtain nuclear extract, cell pellets were washed using hypotonic buffer three times and then lysed for $30 \mathrm{~min}$ at $4{ }^{\circ} \mathrm{C}$ in hypertonic buffer $(20 \mathrm{mM}$ HEPES at $\mathrm{pH} 7.9,0.4 \mathrm{M} \mathrm{NaCl}, 1 \mathrm{mM}$ EDTA, $1 \mathrm{mM}$ phenylmethylsulfonyl fluoride, $1 \mathrm{mM}$ benzamidine, $10 \mu \mathrm{g} / \mathrm{ml}$ leupeptin, $1 \mathrm{mM}$ dithiothreitol, $50 \mathrm{mM}$ sodium fluoride, $0.1 \mathrm{mM}$ sodium orthovanadate) with vortexing from time to time. Supernatants were collected after centrifuging for $15 \mathrm{~min}$ at 13000 r.p.m.

Confocal microscopy. SH-SY5Y, IMR32, and NB-19 cells were seeded onto coverslips in 12-well plates at $10^{5} /$ well and allowed to grow for $24 \mathrm{~h}$, and then either left untreated or treated with $3 \mu \mathrm{M}$ of NSC697923 for $2 \mathrm{~h}$, after which the cells were fixed with $3 \%$ paraformaldehyde in PBS for $15 \mathrm{~min}$ at RT and washed with PBS three times. After fixing, cells were preincubated in PBS containing $0.1 \%$ saponin and $2 \%$ BSA for $10 \mathrm{~min}$, followed by blocked in PBS containing 1:1000 goat $\operatorname{lgG}, 2 \% \mathrm{BSA}$ and $1 \%$ saponin for $20 \mathrm{~min}$. After incubation in PBS containing $1: 300$ anti-p53 antibodies, $1 \%$ saponin, $3 \%$ human FBS, and 5\% BSA overnight at $4{ }^{\circ} \mathrm{C}$, cells were washed with PBS three times and then incubated with (1:2000) Alexa Fluor 555 goat anti-mouse IgG (A-21424; Life Technologies Corporation, Carlsbad, CA, USA) containing $1 \%$ saponin for $30 \mathrm{~min}$. Cells were washed three times again using PBS. The coverslips were then mounted on glass slides using Fluoroprep (BioMérieux, Craponne, France) and sealed with Entellan (Merck, Whitehouse Station, NJ, USA). Images were acquired and processed with Zeiss spindisk confocal microscope (Carl Zeiss AG, Jena, Germany).

Luciferase reporter assay. HEK293T cells were seeded in six-well plates at $3 \times 10^{5} /$ well and co-transfected with MDM2-promoter luciferase reporter plasmid and Renilla-luciferase control plasmid along with Topo-HA-p53 or Topovector plasmid. After $48 \mathrm{~h}$, cells were either left untreated or treated with $0.5 \mu \mathrm{M}$ of NSC697923 for $16 \mathrm{~h}$ and lysed in $150 \mu \mathrm{l}$ of $1 \times$ passive lysis buffer (Promega, Madison, WI, USA) for $20 \mathrm{~min}$. After centrifuging at 13000 r.p.m. for $15 \mathrm{~min}, 10 \mu \mathrm{l}$ of lysate was used to perform luciferase reporter assay using the Dual-Luciferase Reporter Assay System (Promega). The relative luciferase activity was determined by dividing the firefly luciferase activity by the Renilla luciferase activity. The experiment was performed in duplicate.

Antitumor efficacy of NSC697923 in an orthotopic mouse model of NB. All the animals used in this study (5- to 6-week-old female athymic $\mathrm{Ncr}$ nude mice) were purchased from Taconic (Taconic, Hudson, NY, USA) and maintained under barrier conditions (pathogen-free conditions provided by plastic cages with sealed air filters). Preclinical mouse model of NB was established by orthotopic (intrarenal) implantation of the NB cells as described previously. ${ }^{4}$ Briefly, $1.5 \times 10^{6}$ luciferase-transduced SH-SY5Y or NGP cells were injected under the renal capsule and toward the superior pole of the left kidney of mice. After allowing them to engraft for 2-3 weeks, mice bearing tumors were randomized into two groups: DMSO control group and NSC697923 treatment group ( $5 \mathrm{mg} / \mathrm{kg}$ by intraperitoneal injection everyday for 10 days). For SH-SY5Y xenografts, both control and experimental groups contained four mice, whereas for NGP xenografts, each group contained three mice. At the end of the treatment, all mice were killed. Tumors and the right kidney (control) were resected, weighed, and photographed. All mice were housed in a pathogen-free environment and handled according to protocols approved by Institutional Animal Care and Use Committee of Baylor College of Medicine.

Statistical analysis. All values were presented as mean \pm S.D. All statistical tests were two-sided. A $P$-value $<0.05$ was considered statistically significant. A two-tailed Student's $t$-test was used to determine the statistical significance of in vitro drug treatment experiments and to compare tumor sizes between treated and untreated xenografted NB mice.

\section{Conflict of Interest}

The authors declare no conflict of interest.

Acknowledgements. We thank Dr. Andrew Davidoff (St. Judes's Children's Research Hospital, Memphis, TN, USA) and Dr. Robert Seeger (Children's Hospital of Los Angeles, Los Angeles, CA, USA) for providing the NB cell lines described in this article. We also thank Kristine Yang for editing our manuscript. This work was supported by the NIH/NINDS grant 1R01NS072420 (JY), 1R21NS085467 (JY), P30 CA125123 pilot project award (JY), the Leading Academic Discipline Project of Beijing (FL) and the 111 Project (B07001; FL). Jin Cheng is a recipient of China Scholarship Council training grant.

1. Brodeur GM. Neuroblastoma: biological insights into a clinical enigma. Nat Rev Cancer 2003; 3: 203-216.

2. Maris JM. Recent advances in neuroblastoma. N Engl J Med 2010; 362: 2202-2211.

3. Ganeshan VR, Schor NF. Pharmacologic management of high-risk neuroblastoma in children. Paediatr Drugs 2011; 13: 245-255.

4. Hara J. Development of treatment strategies for advanced neuroblastoma. Int J Clin Oncol 2012; 17: 196-203.

5. Morgenstern DA, Baruchel S, Irwin MS. Current and future strategies for relapsed neuroblastoma: challenges on the road to precision therapy. I Pediatr Hematol Oncol 2013; 35: 337-347.

6. Xue C, Haber M, Flemming C, Marshall GM, Lock RB, MacKenzie KL et al. p53 determines multidrug sensitivity of childhood neuroblastoma. Cancer Res 2007; 67: 10351-10360.

7. Bieging KT, Attardi LD. Deconstructing p53 transcriptional networks in tumor suppression. Trends Cell Biol 2012; 22: 97-106.

8. Vogelstein B, Lane D, Levine AJ. Surfing the p53 network. Nature 2000; 408: 307-310.

9. Brooks CL, Gu W. p53 ubiquitination: Mdm2 and beyond. Mol Cell 2006; 21: 307-315.

10. Marine JC, Lozano G. Mdm2-mediated ubiquitylation: p53 and beyond. Cell Death Differ 2010; 17: 93-102.

11. Hosoi G, Hara J, Okamura T, Osugi Y, Ishihara S, Fukuzawa M et al. Low frequency of the p53 gene mutations in neuroblastoma. Cancer 1994; 73: 3087-3093.

12. Becker K, Marchenko ND, Maurice M, Moll UM. Hyperubiquitylation of wild-type p53 contributes to cytoplasmic sequestration in neuroblastoma. Cell Death Differ 2007; 14: 1350-1360.

13. Moll UM, LaQuaglia M, Benard J, Riou G. Wild-type p53 protein undergoes cytoplasmic sequestration in undifferentiated neuroblastomas but not in differentiated tumors. Proc Natl Acad Sci USA 1995; 92: 4407-4411.

14. Laine A, Topisirovic I, Zhai D, Reed JC, Borden KL, Ronai Z. Regulation of p53 localization and activity by Ubc13. Mol Cell Biol 2006; 26: 8901-8913.

15. Hofmann RM, Pickart CM. Noncanonical MMS2-encoded ubiquitin-conjugating enzyme functions in assembly of novel polyubiquitin chains for DNA repair. Cell 1999; 96: 645-653

16. McKenna S, Spyracopoulos L, Moraes T, Pastushok L, Ptak C, Xiao W et al. Noncovalent interaction between ubiquitin and the human DNA repair protein Mms2 is required for Ubc13-mediated polyubiquitination. J Biol Chem 2001; 276: 40120-40126.

17. Ye Y, Rape M. Building ubiquitin chains: E2 enzymes at work. Nat Rev Mol Cell Biol 2009; 10: $755-764$.

18. Andersen PL, Zhou H, Pastushok L, Moraes T, McKenna S, Ziola B et al. Distinct regulation of Ubc13 functions by the two ubiquitin-conjugating enzyme variants Mms2 and Uev1A. J Cell Biol 2005; 170: 745-755.

19. Yamamoto M, Okamoto T, Takeda K, Sato S, Sanjo H, Uematsu S et al. Key function for the Ubc13 E2 ubiquitin-conjugating enzyme in immune receptor signaling. Nat Immunol 2006; 7: 962-970.

20. Topisirovic I, Gutierrez GJ, Chen M, Appella E, Borden KL, Ronai ZA. Control of p53 multimerization by Ubc13 is JNK-regulated. Proc Natl Acad Sci USA 2009; 106 : 12676-12681

21. Scheper J, Guerra-Rebollo M, Sanclimens G, Moure A, Masip I, Gonzalez-Ruiz D et al. Protein-protein interaction antagonists as novel inhibitors of non-canonical polyubiquitylation. PLoS One 2010; 5: e11403.

22. Tsukamoto $\mathrm{S}$, Takeuchi $\mathrm{T}$, Rotinsulu $\mathrm{H}$, Mangindaan RE, van Soest RW, Ukai $\mathrm{K}$ et al. Leucettamol A: a new inhibitor of Ubc13-Uev1A interaction isolated from a marine sponge, Leucetta aff. microrhaphis. Bioorg Med Chem Lett 2008; 18: 6319-6320.

23. Ushiyama $\mathrm{S}$, Umaoka $\mathrm{H}$, Kato $\mathrm{H}$, Suwa $\mathrm{Y}$, Morioka $\mathrm{H}$, Rotinsulu $\mathrm{H}$ et al. Manadosterols $A$ and $B$, sulfonated sterol dimers inhibiting the Ubc13-Uev1A interaction, isolated from the marine sponge Lissodendryx fibrosa. J Nat Prod 2012; 75: 1495-1499.

24. Ardecky R, Madiraj C, Matsuzawa S, Zou J, Ganji S, Pass I et al. Selective UBC13 Inhibitors. Probe Reports from the NIH Molecular Libraries Program. National Center for Biotechnology Information (US): Bethesda (MD), 2010-2012.

25. Pulvino M, Liang $\mathrm{Y}$, Oleksyn D, DeRan M, Van Pelt E, Shapiro J et al. Inhibition of proliferation and survival of diffuse large B-cell lymphoma cells by a small-molecule inhibitor of the ubiquitin-conjugating enzyme Ubc13-Uev1A. Blood 2012; 120: 1668-1677.

26. Park JR, Eggert A, Caron H. Neuroblastoma: biology, prognosis, and treatment. Hematol Oncol Clin North Am 2010; 24: 65-86.

27. Moll UM, Ostermeyer AG, Haladay R, Winkfield B, Frazier M, Zambetti G. Cytoplasmic sequestration of wild-type p53 protein impairs the G1 checkpoint after DNA damage. Mol Cell Biol 1996; 16: 1126-1137.

28. Fukushima T, Matsuzawa S, Kress CL, Bruey JM, Krajewska M, Lefebvre $S$ et al. Ubiquitin-conjugating enzyme Ubc13 is a critical component of TNF receptor-associated factor (TRAF)-mediated inflammatory responses. Proc Natl Acad Sci USA 2007; 104: $6371-6376$ 
29. Sayama K, Yamamoto M, Shirakata Y, Hanakawa $Y$, Hirakawa S, Dai $X$ et al. E2 Polyubiquitin-conjugating enzyme Ubc13 in keratinocytes is essential for epidermal integrity. J Biol Chem 2010; 285: 30042-30049.

30. Stegh $\mathrm{AH}$. Targeting the $p 53$ signaling pathway in cancer therapy-the promises, challenges and perils. Expert Opin Ther Targets 2012; 16: 67-83.

31. Bykov VJ, Issaeva N, Shilov A, Hultcrantz M, Pugacheva E, Chumakov P et al. Restoration of the tumor suppressor function to mutant p53 by a low-molecular-weight compound. Nat Med 2002; 8: 282-288.

32. Bykov VJ, Zache N, Stridh H, Westman J, Bergman J, Selivanova G et al. PRIMA-1(MET) synergizes with cisplatin to induce tumor cell apoptosis. Oncogene 2005; 24: 3484-3491.

33. Shangary S, Ding K, Qiu S, Nikolovska-Coleska Z, Bauer JA, Liu M et al. Reactivation of p53 by a specific MDM2 antagonist (MI-43) leads to p21-mediated cell cycle arrest and selective cell death in colon cancer. Mol Cancer Ther 2008; 7: 1533-1542.

34. Shangary S, Wang S. Small-molecule inhibitors of the MDM2-p53 protein-protein interaction to reactivate p53 function: a novel approach for cancer therapy. Annu Rev Pharmacol Toxicol 2009; 49: 223-241.

35. Fan Y, Cheng J, Vasudevan SA, Dou J, Zhang H, Patel RH et al. USP7 inhibitor P22077 inhibits neuroblastoma growth via inducing p53-mediated apoptosis. Cell Death Dis 2013; 4: 867.

36. Mutka SC, Yang WQ, Dong SD, Ward SL, Craig DA, Timmermans PB et al. Identification of nuclear export inhibitors with potent anticancer activity in vivo. Cancer Res 2009; 69: 510-517.
37. Inoue H, Kauffman M, Shacham S, Landesman Y, Yang J, Evans CP et al. CRM1 blockade by selective inhibitors of nuclear export attenuates kidney cancer growth. J Urol 2013; 189: 2317-2326.

38. Ki YW, Park JH, Lee JE, Shin IC, Koh HC. JNK and p38 MAPK regulate oxidative stress and the inflammatory response in chlorpyrifos-induced apoptosis. Toxicol Lett 2013; 218: 235-245.

39. Maris JM, Hogarty MD, Bagatell R, Cohn SL. Neuroblastoma. Lancet 2007; 369: 2106-2120.

40. Fan $\mathrm{Y}$, Cheng J, Vasudevan SA, Patel RH, Liang $\mathrm{L}, \mathrm{Xu} X$ et al. TAK1 inhibitor 5Z-7-oxozeaenol sensitizes neuroblastoma to chemotherapy. Apoptosis 2013; 18 : 1224-1234.

41. Patterson DM, Shohet JM, Kim ES. Preclinical models of pediatric solid tumors (neuroblastoma) and their use in drug discovery. Curr Protoc Pharmacol 2011; Chapter 14 Unit 14.17 .

(c) (i) (2) Cell Death and Disease is an open-access journal published by Nature Publishing Group. This work is licensed under a Creative Commons Attribution-NonCommercialShareAlike 3.0 Unported License. To view a copy of this license, visit http://creativecommons.org/licenses/by-nc-sa/3.0/

Supplementary Information accompanies this paper on Cell Death and Disease website (http://www.nature.com/cddis) 